\title{
Haematometra in one half of the uterus or rudimentary horn?
}

\author{
Suniti Rawal, Josie Baral, Meeta Singh, Samira Khan, \\ Beemba Shakya, Rashmi Choudhary, Mira Thapa, Varsha Anand. \\ Dept of Obs/Gyn, TU Teaching Hospital
}

\begin{abstract}
A unicornuate uterus with functioning and non communicating rudimentary horn is a rare Mullerian abnormality, difficult to diagnose at times usually low in the list of differential diagnosis for pelvic pain and dysmenorrhea.

A 22 years $P_{1}$ presented with severe lower abdominal pain and dysmenorrhoea, following laparotomy that was done for endometriotic cyst of left ovary 7 months back. Radiographic studies revealed the haematometra in the rudimentary horn with normal uterus, right ovary and the tube.

Laparotomy with drainage of haematometra and excision of septum along with the reconstruction of uterine cavity was performed thus anatomizing it with the cavity of the rudimentary horn. Both the intra and the post operative period were uneventful. She was discharged on OCP along with the advice to follow up regularly. She is asymptomatic till date.
\end{abstract}

Key words: Endometriosis, haematometra, rudimentary horn,

\section{Introduction}

It is natural that any organ of the body which has such abnormal development as shown by the uterus and the vagina should reveal anatomical variation from that of normal. Non communicating rudimentary horn with a functioning endometrial cavity in a unicornate uterus is one of the rare müllerian abnormalities. Various types of uterovaginal malformations do occur in $0.16 \%$ of the women. The frequency of this pathology is approximately $1 / 100,000 .{ }^{1}$ These patients usually present with dysmenorrhea, dyspareunia and chronic pelvic pain because of endometriosis. ${ }^{2,3}$ At times also with acute abdominal symptoms following distention and torsion of the noncommunicating rudimentary horn.

It is not at all surprising that such an anomaly is usually unnoticed during childhood, until they attain menarche, when one or the other symptoms does appear that sometimes may be a boon in disguise, though sometimes, the person can still pass through the adult life successfully fulfilling all the obligations of raising a family in spite of such a handicap. It does lend a considerable interest to a condition which after all is not so common.

\section{Case Report}

A twenty two years old primipara, a housewife from Dhading who had undergone emergency laparotomy 7 months back for twisted left adenexal mass or ruptured haemorrhagic cyst (fig1) was readmitted with the complaints of persistent spasmodic pain in the left iliac fossa. The pain occurred about 5-6 days prior to menstruation and lasted 8-9 days afterwards. This indicated her to suffer almost 20 days of her regular menstruation in normal cycles of $28 \pm 2$ days with an average flow for 5-6day since her menarche at age of 14 years. She was $\mathrm{P}_{1}$ and had a female child of 15 months, delivered vaginally at term.

The history dates back to 7-8 months when she had attended the Emergency Department with spasmodic pain in the left iliac fossa for 2 days. This pain occurred 8 months after the delivery of her child and had to

Correspondence

Dr Suniti Rawal

Lecturer Dept of Obs/Gyn, TU Teaching Hospital, Kathmandu.

Email: sunudinurawal@yahoo.com 
undergo emergency laparotomy. Per operatively right tube and right ovary were normal. There was left chocolate cyst of $6 \times 6 \mathrm{~cm}$ firmly adhered to the fundus and posterior surface of uterus, which ruptured releasing 'anchovy sauce' like content on separation. Leaving rudimentary horn as such, left salphingooophorectomy was done removing the chocolate cyst (Fig 1). Histopathology was consistent with chronic salpingitis and endometriotic cyst.

Recurrence of pain brought her back to Gynaecological Out Patient Department (GOPD). She was prescribed injection DMPA (Depot medroxy progesterone acetate), $150 \mathrm{mg}$ intramuscularly every 3 monthly and this did not relieve the pain either. Vaginal examination detected a tender cystic mass measuring about 10x8 $\mathrm{cm}$ in the left fornix. In (fig 2) transvaginalsonography (TVS), a cystic mass with collection inside measuring $6.5 \times 7.4 \mathrm{~cm}$ with thick wall was visualized adherent to the empty uterus on the left side. This somewhat made us rethink about the possibility of haematometra in rudimentary horn and was planned for abdominal drainage. All the preoperative investigations were normal and blood group was A+ve. So, under spinal anesthesia, laparotomy was done. On opening the abdomen adhesion was seen between the omentum, bowel and left horn of uterus and adhesiolysis was done for proper visualization. The uterus was unicornuate, normal in size, the right ovary was normal but the right tube was inflamed. Rudimentary horn on the left side was longitudinally incised in the anterior aspect draining $50 \mathrm{ml}$ of thick tarry blood (fig3). Instead of excising, the rudimentary horn after exposing the cavity (fig4), this was unified with the main uterus (demarcated by passing a sound: Fig 5) anatomizing both the uterus after the removing wedge of tissue intervening between them. The uterine cavity was reconstructed by repairing it in 3 layers by vicryl number1 with continuous locking stitches securing proper hemostasis.

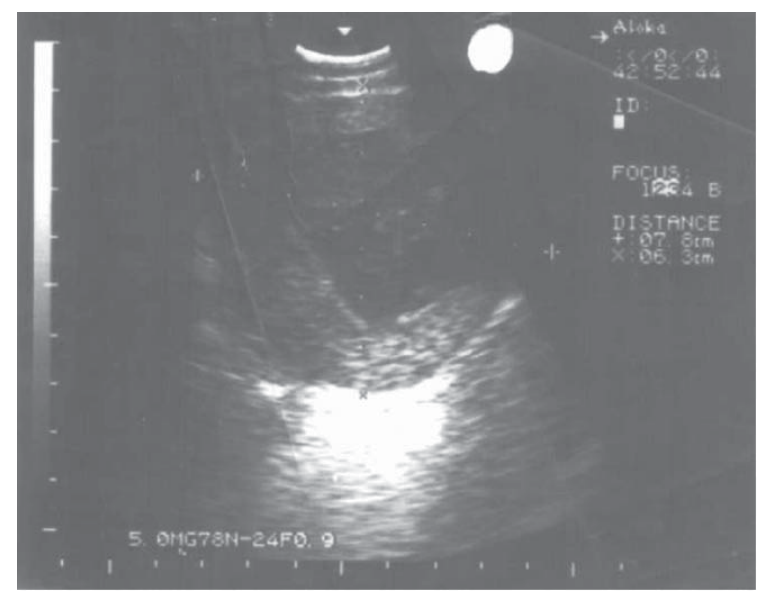

Fig 1. USG picture demonstrating blood collection beside the uterus

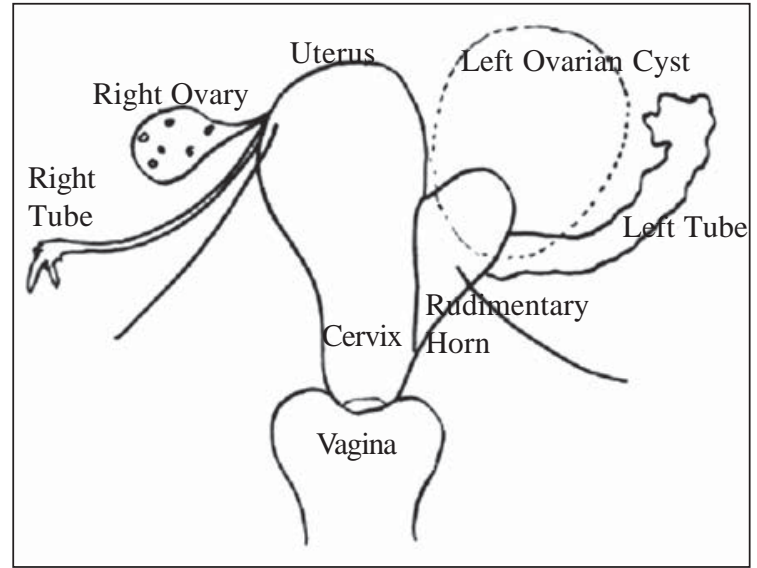

Fig2. Schematic diagram of the uterus and the rudimentary horn (left), which looks smaller during lactational amenorrhea.

Her post operative period was uneventful. She was discharged on $4{ }^{\text {th }}$ POD. Sutures were removed on 10th POD and she was put on OCPs for a period of 3 months and was asked for follow up. Patient has not returned for follow up yet. Menorrhagia can be expected from this unified cavity.

\section{Discussion}

Based on the degree of failure of normal uterine development, the American Fertility Society (AFS) in 1988 classified the Müllerian anomalies and according to that this patient was in Class II and according to the modified AFS classification of uterovaginal anomalies based on the embryological consideration she was in Class III, that is the disorder of the lateral fusion of the Müllerian duct, which is unicornuate uterus with a non communicating functioning endometrial cavity in the rudimentary horn.

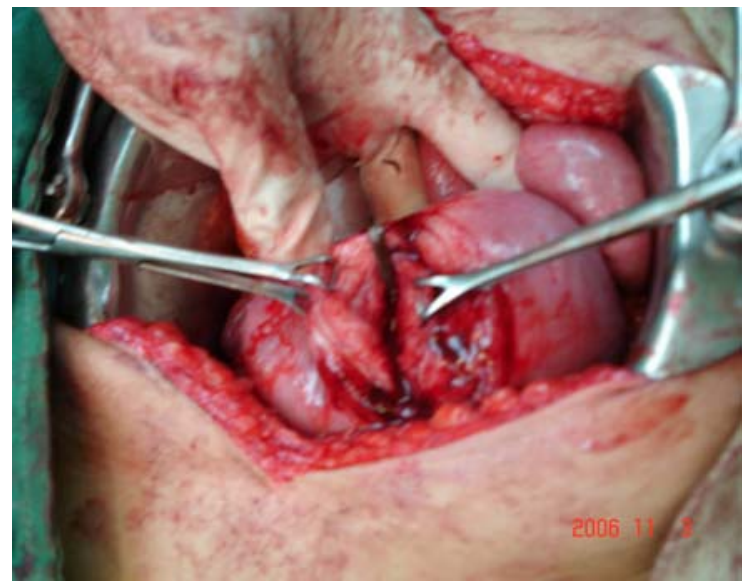

Fig 3. Hematometra draining. 


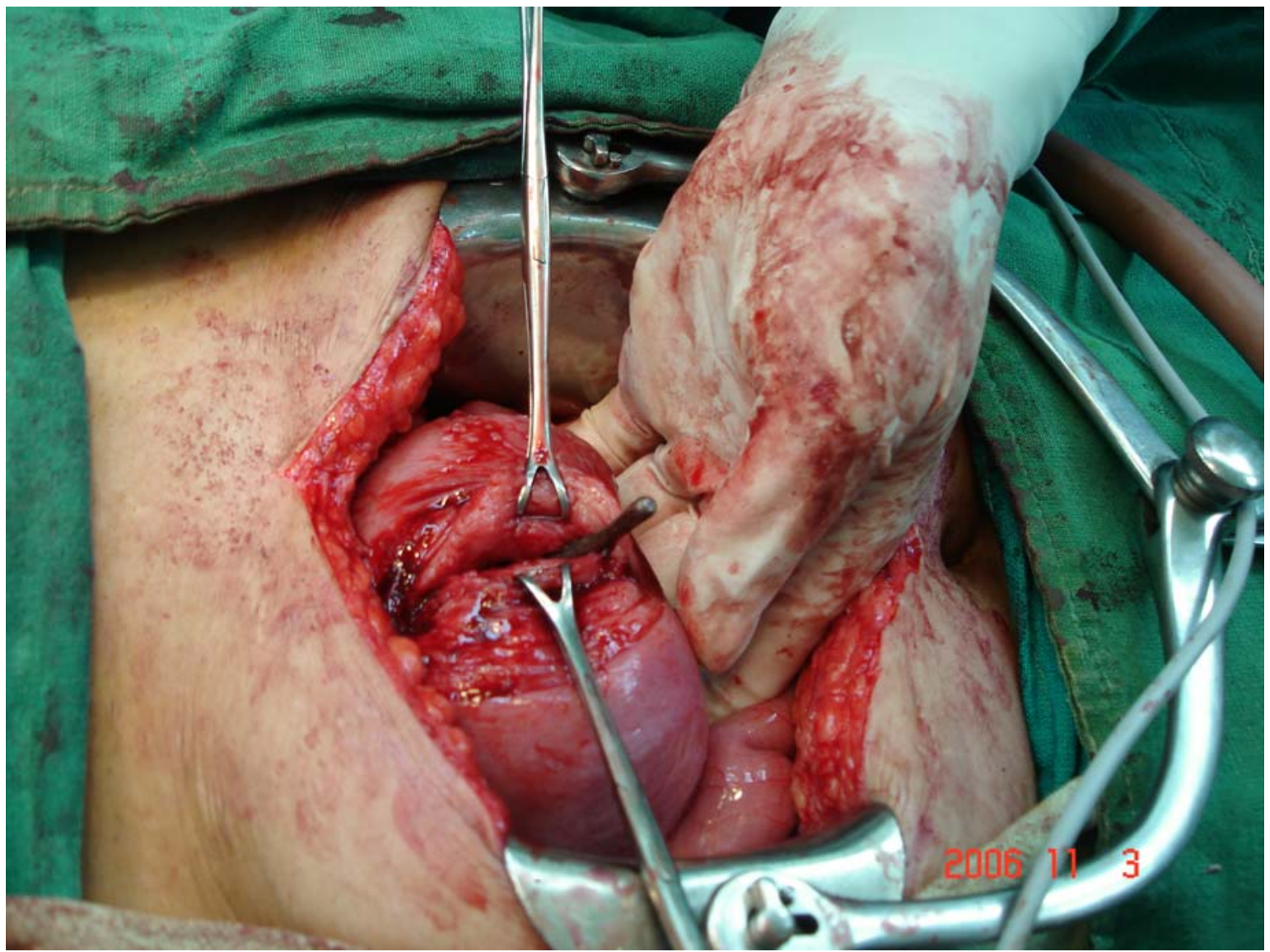

Fig 4. Sound passed from below, exposing the normal uterine cavity.

The endometrial tissue that is present in the rudimentary horn can appear immature or rarely show the evidence of the cyclical response to the ovarian hormones as was seen in this patient.

Severe dysmenorrhoea with pain in the lower abdomen is usually encountered in these patients due to the collection of the menstrual blood inside the endometrial cavity of the rudimentary horn. Especially in the ones that are non-communicating, as seen in our patient, cryptomenorrhoea is overlooked due to the normal menstruation occurring from the patent uterine cavity. ${ }^{4}$

It's surprising but real that a haematometra of non communicating variety was detected at pregnancy and after caesarean in a 30-year-old in another woman who complained of increasing dysmenorrhoea and progressive right lower-quadrant pain. ${ }^{6}$ More over rudimentary uterine horn have been detected in a previously hysterectomies patient as well. ${ }^{7}$

Pain is due to cyclic accumulation of the trapped blood. Usually this symptom occurs close to menarche. In our case it occurred 8 years following menarche and that too was not given full attention at the time of removing the chocolate cyst. Haematometra causes the regurgitation of menstrual blood to the ovary leading to the development of endometriosis and the endometrioma. For this reason, severe dysmenorrhoea in normally menstruating woman must not be taken lightly, as these may indicate non-communicated rudimentary horn with functional endometrium and haematometra. ${ }^{8}$

Laparoscopy guided USG is an invaluable tool in defining anatomy as there's always some risk of missing the true diagnosis in cases of uterine abnormalities, even by direct inspection. ${ }^{9}$ To date laparotomy with resection of the rudimentary horn has been the treatment of choice, but many a literature have now stated about laparoscopy being the effective surgical approach with the help of which not only is the diagnosis confirmed but the rudimentary horns are resected without increased risk to the patient and with some potential benefit. ${ }^{9}$ Consideration of prophylactic resection of a noncommunicating uterine horn should also be considered in an asymptomatic, reproductiveage patient with this rare müllerian anomaly. ${ }^{10}$

\section{Conclusion}

Hematometra in a non - communicating rudimentary horn with a functioning endometrium gives rise to dysmenorrhoea, pelvic pain and pelvic endometriosis in a woman at any age or parity making a differential diagnosis. 


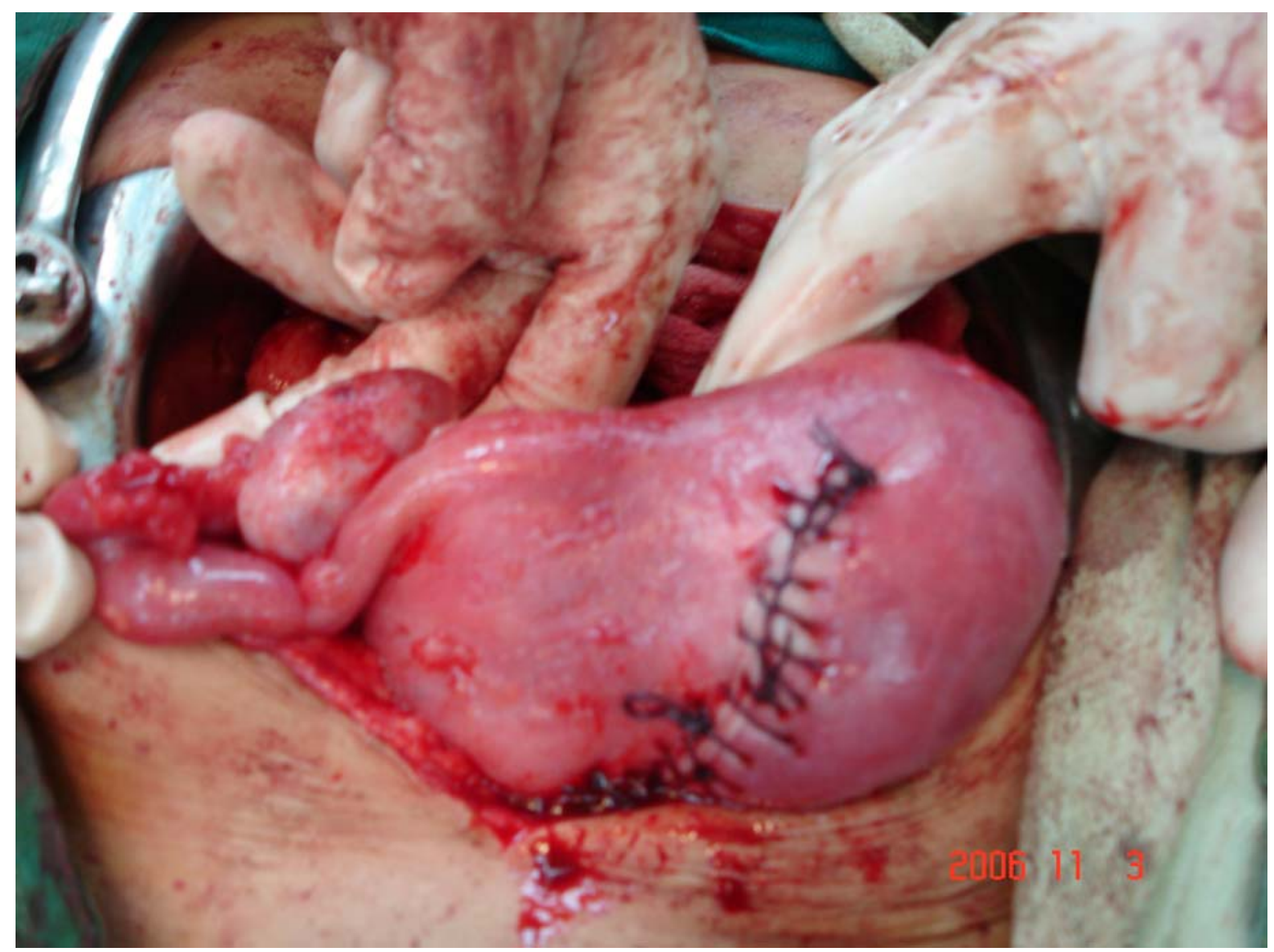

Fig 5. Unified uterus showing ovary and tubes on the right side.

\section{References}

1. Atmaca R, Germen AT, Burak F, Kafkasli A. Acute abdomen in a case with noncommunicating rudimentary horn and unicornuate uterus. JSLS. 2005 Apr-Jun; 9(2):235-7.

2. Sanfilippo JS, Wakim NG, Schikler KN, Yussman MA. Endometriosis in association with uterine anomaly. Am J Obstet Gynecol. 1986 Jan;154(1):39-43

3. Goluda M, St Gabryú M, Ujec M, Jedryka M, Goluda C. Bicornuate rudimentary uterine horns with functioning endometrium and complete cervical-vaginal agenesis coexisting with ovarian endometriosis: a case report. Fertil Steril. 2006 Aug; 86(2):462.e9-11. Epub 2006 Jun 27

4. Dadhwal V, Mittal S, Kumar S, Barua A. Hematometra in postmenarchal adolescent girls: a report of two cases. Gynecol Obstet Invest. 2000; 50(1):67-9

5. Zeibekis N, Bernaschek G, Spernol R, Schaller A. The pregnant and non pregnant rudimentary horn of a uterus. Geburtshilfe Frauenheilkd. 1980 May; 40(5):4015.
6 Chang CY, Chang SY, Changchien CC, Lui CC, Huang HW. Hematometra of the rudimentary horn of a unicornuate uterus resulting from cesarean section. Am J Obstet Gynecol. 2001 Nov; 185(5):1263-4

7. Stitely ML, Hopkins K. Laparoscopic removal of a rudimentary uterine horn in a previously hysterectomized patient. JSLS. 2006 Apr-Jun; 10(2):257-8.

8. Fujimoto VY, Klein NA, Miller PB. Late-onset hematometra and hematosalpinx in a woman with a noncommunicating uterine horn. A case report. J Reprod Med. 1998 May;43(5):465-7.

9. Tanaka Y, Asada H, Uchida H, Maruyama T, Kuji N, Sueoka K, Yoshimura Y. Case of iatrogenic dysmenorrhea in non-communicating rudimentary uterine horn and its laparoscopic resection. J Obstet Gynaecol Res. 2005 Jun; 31(3):242-6.

10. Fedele L, Bianchi S, Zanconato G, Berlanda N, Bergamini V. Laparoscopic removal of the cavitated noncommunicating rudimentary uterine horn: surgical aspects in 10 cases. Fertil Steril. 2005 Feb; 83(2):432-6 